\title{
Accuracy of sonographic fetal weight estimation in a tertiary care hospital in Bharatpur, Nepal
}

\author{
V Natraj Prasad, Pratik Poudel, Pramod Kumar Chhetry \\ Department of Radiodiagnosis, College of Medical Sciences- Teaching Hospital, Bharatpur, Nepal
}

\section{Correspondence \\ Dr. Pratik Poudel \\ Department of Radiodiagnosis, \\ College of Medical Sciences- \\ Teaching Hospital, Bharatpur, Nepal \\ Email: \\ pratikpoudel350@gmail.com}

DOI: http://dx.doi.org/10.3126/ jemsn.v12i4.16374

Article received: Aug $5^{\text {th }} 2016$ Article accepted: Sept $2^{\text {nd }} 2016$

\begin{abstract}
Background \& Objectives: Among the various methods used in the estimation of intrauterine fetal weight, sonographic fetal weight estimation is the one and has become an important component of antenatal care. The study was conducted with objective to assess the accuracy and reliability of ultrasound estimation of fetal weight in women with a singleton term pregnancy. Materials \& Methods: This was a prospective cross-sectional study of 120 women with singleton term pregnancies. Ultrasound estimated fetal weight was calculated by measuring the biparietal diameter and abdominal circumference. The estimated fetal weight was compared to the actual birth weight post delivery. The correlation between estimated fetal weight and actual birth weight was assessed by Pearson's correlation coefficient and the accuracy of sonographic fetal weight estimation was measured using mean error, mean absolute error, mean percentage error, mean absolute percentage error and proportion of estimates within $10 \%$ of actual birth weight. Results were tested at error level set at $p \leq 0.05$. Results: Mean estimated and actual birth weights were $2863.5 \pm 441.9 \mathrm{~g}$ and $2822.5 \pm$ $407.7 \mathrm{~g}$ respectively. There was a strong positive correlation between estimated fetal weight and actual birth weight $(r=0.71, p<0.001)$. The mean percentage error and mean absolute percentage error of ultrasound fetal weight estimations were $1.9 \pm 11.4 \%$ and $8.8 \pm 7.5 \%$ respectively. Conclusion: Sonographically estimated fetal weight had strong positive correlation with actual birth weight and thus sonography can be used in the estimation of fetal weight for the better perinatal outcome.

Key words: Actual birth weight; Ultrasonographically estimated fetal weight
\end{abstract}

Citation: Prasad VN, Poudel P, Chhetry PK. Accuracy of sonographic fetal weight estimation in a tertiary care hospital in Bharatpur, Nepal. JCMS Nepal. 2016;12(4):174-8.

\section{INTRODUCTION}

During pregnancy, one of the important factors in deciding the obstetrical management and the fetal outcome is the estimation of accurate fetal weight. There are several methods of estimating intrauterine fetal weight like tactile assessment of the fetal size, risk factors assessment, maternal self estimation and ultrasonography. ${ }^{1,2}$ The advantage of the ultrasonographic technique is that it relies on linear and/or planar measurement of in-utero fetal dimensions that can be defined objectively and are reproducible. ${ }^{3}$

Multiple formulae have been developed for the estimation of birth weight using ultrasound measurement; using abdominal circumference (AC) alone, $\mathrm{AC}$ and biparietal diameter (BPD) and $\mathrm{AC}$,
BPD and femur length. At present, fetal ultrasound is extensively used to estimate the fetal weight. ${ }^{4}$ In Nepal, Hadlock's formula is very commonly used. ${ }^{5}$ Many studies have been carried out in America, Europe, and Asia which compared sonographically estimated fetal weights (EFWs) with actual birth weights (ABWs) of fetuses in order to determine the accuracy of EFWs in the respective population. ${ }^{6}$

To the best of our knowledge, data on the weight of Nepalese fetuses are sparse, and data on the correlation of sonographically estimated fetal weights with actual birth weights, in order to establish the effectiveness of estimation models in the country, is even sparser. This study was, therefore, carried out to determine the accuracy and thus the reliability of Hadlock (BPD, AC) fetal 
weight estimation algorithm in College of Medical Sciences, Bharatpur.

\section{MATERIALS AND METHODS}

This was a prospective cross-sectional study conducted during the period January 2015 to January 2016 at College of Medical SciencesTeaching Hospital (COMS TH), Bharatpur. The study included 120 normal antenatal women at term pregnancy (37 to 42 weeks of gestation) who were assessed clinically at the department of obstetrics and gynaecology and referred to the radiology department for ultrasonography. Informed consent of the patient and approval from the ethical committee of the institution was obtained prior to the procedure. The exclusion criteria were multiple pregnancy, IUGR (Intrauterine Growth Retardation), stillbirth, congenital fetal malformations, hydrops fetalis, diabetes mellitus in mother and delivery after seven days of ultrasonic fetal weight estimation.

Ultrasonography of each case included in the study was done using Samsung Medison ACCUVIX A30 ultrasound equipment with a scanner frequency of 3.5 $\mathrm{MHz}$ to assess fetal viability, fetal presentation, biparietal diameter, head circumference, abdominal circumference, femur length, and gestational age. Hadlock formula (BPD, AC) was used to estimate the fetal weight, the software of which is installed in our ultrasound machine. The machine calculated the fetal weight automatically after measuring the BPD and AC.

Following data were collected: maternal age, gestational age at delivery, estimated fetal weights, birth weights of infant, maternal parity status, mode of delivery, gender of the newborn and intrauterine orientation of the fetus. All data collected from the study were recorded and thereafter keyed into the Statistical Package for Social Sciences (SPSS) computer software version 16.0 for windows. Microsoft word and Excel were used to generate graphs, tables etc.

Estimated fetal weight obtained by Hadlock formula was compared with the newborn's actual birth weight after immediate delivery in the labor room or operational theater of COMS-TH.

Both descriptive statistics such as mean and standard deviation (SD) and inferential statistics such as Pearson's correlation (r) were used to interpret the results. Test for significance of results was set at $p \leq 0.05$.

Different measures of accuracy were used in this statistical analysis and these include mean error, mean absolute error, mean percentage error, mean absolute percentage error and the proportion of estimates within $\pm 10 \%$ of actual birth weight.

\section{RESULTS}

One hundred and twenty pregnant women were recruited for the study. The mean maternal age was $24.2 \pm 4.5$ years (range 17 to 37 years) (Table 1). The mean gestational age was $39.3 \pm 1.6$ weeks (range: 37 to 41.9 weeks) (Table 1).

The mean ultrasound estimated birth weight was $2863.5 \pm 441.9 \mathrm{~g}$ (range: 1757 to $3840 \mathrm{~g}$ )(Table 1 ). In the study, $23.3 \%$ babies had birth weight of less than $2500 \mathrm{~g}, 76.7 \%$ had birth weight of 2500 to $4000 \mathrm{~g}$, while none weighed higher than $4000 \mathrm{~g}$. The mean actual birth weight of new-borns was $2822.5 \pm 407.7 \mathrm{~g}$ (range: $2000-4000 \mathrm{~g}$ )(Table 1). Among the newborns, 30\% had birth weights of less than $2500 \mathrm{~g}, 70 \%$ had birth weights of 2500 $4000 \mathrm{~g}$, while none of the newborn weighed higher than $4000 \mathrm{~g}$.

The ultrasound estimated fetal weight (EFW) had a strong positive correlation with actual birth weight (ABW) of the newborns $(r=0.71, p<0.001)$. The scatter diagram of their relationship is shown in figure 1.

Table 1 : Maternal and infant demographics

\begin{tabular}{|c|c|c|c|}
\hline \multirow[b]{2}{*}{ Characteristics } & \multirow[b]{2}{*}{$\begin{array}{c}\text { Mean } \pm \\
\text { SD }\end{array}$} & \multicolumn{2}{|c|}{ Range } \\
\hline & & $\begin{array}{l}\text { Mini } \\
\text { mum }\end{array}$ & $\begin{array}{l}\text { Maxi } \\
\text { mum }\end{array}$ \\
\hline $\begin{array}{l}\text { Maternal age } \\
\text { (years) }\end{array}$ & $24.2 \pm 4.5$ & 17.0 & 37.0 \\
\hline $\begin{array}{l}\text { Gestational age } \\
\text { at delivery } \\
\text { (weeks) }\end{array}$ & 393 & 37.0 & 41.9 \\
\hline $\begin{array}{l}\text { Estimated birth } \\
\text { weight (grams) }\end{array}$ & $\begin{array}{c}2863.5 \pm 4 \\
41.9\end{array}$ & $\begin{array}{c}1757 . \\
0\end{array}$ & $\begin{array}{c}3840 . \\
0\end{array}$ \\
\hline $\begin{array}{l}\text { Actual birth } \\
\text { weight (grams) }\end{array}$ & $\begin{array}{c}2822.5 \pm 4 \\
07.7\end{array}$ & $\begin{array}{c}2000 . \\
0\end{array}$ & $\begin{array}{c}4000 . \\
0\end{array}$ \\
\hline
\end{tabular}

Table 2: Accuracy of the method

\begin{tabular}{lcc} 
Overall & Mean & SD \\
Mean error (gram) & 41.0 & 325. \\
& & 2 \\
Mean absolute error (gram) & 246.9 & 214. \\
& & 7 \\
Mean percentage error & 1.9 & 11.4 \\
$\begin{array}{l}\text { Mean absolute percent } \\
\text { error }\end{array}$ & 8.8 & 7.5 \\
$\begin{array}{l}\text { Accurate (within } 10 \% \text { of } \\
\text { ABW) }\end{array}$ & $65 \%$ & \\
\hline
\end{tabular}




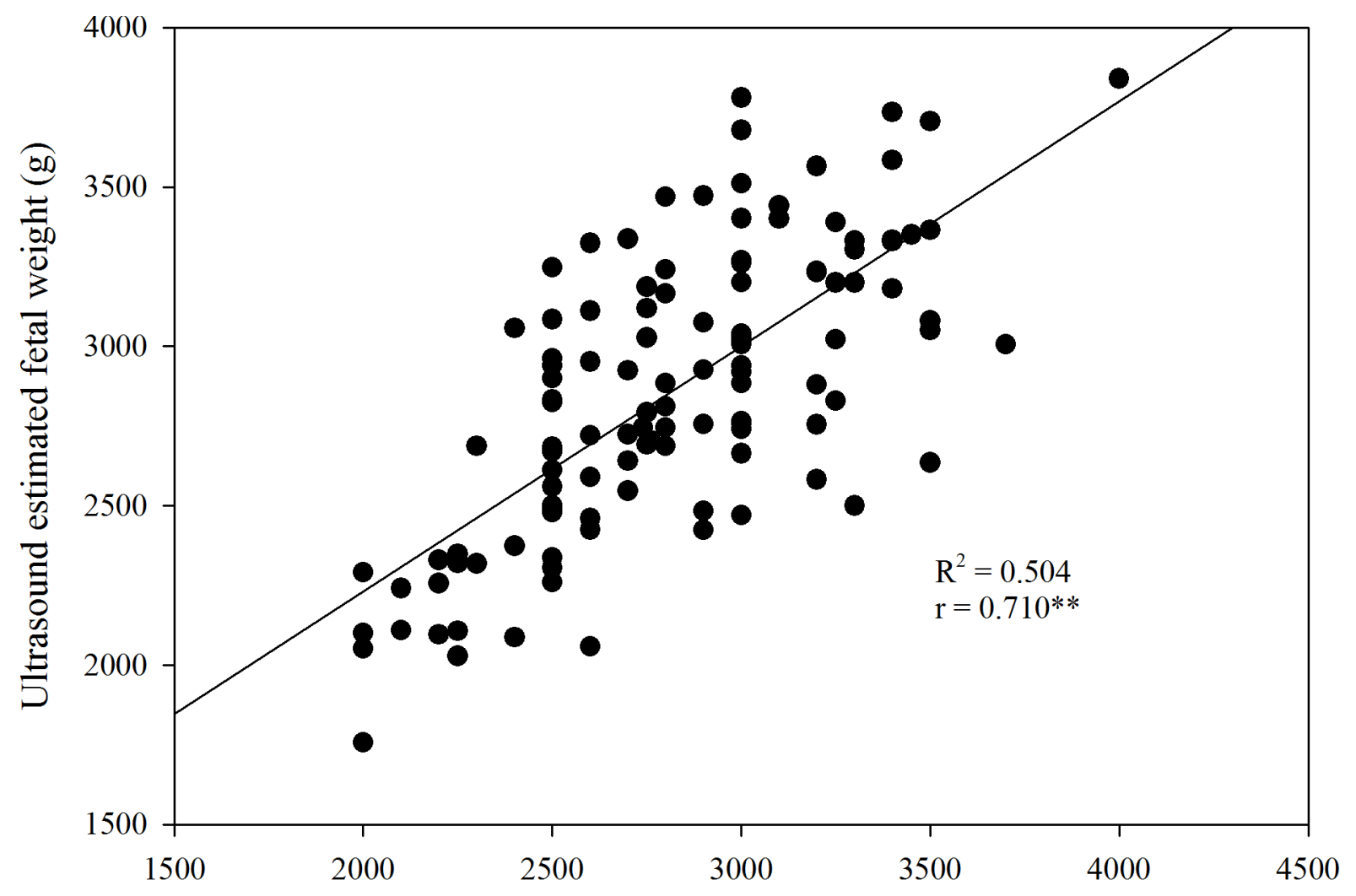

Actual birth weight $(\mathrm{g})$

Figure 1: Graph showing the relation between ultrasound estimated fetal weight (EFW) and actual birth weight (ABW) (in grams) and a linear association between both variables. The continuous line is the regression line.

The mean error in the estimation of birth weight was $41.0 \mathrm{~g}[-865,780 \mathrm{~g}]$. The mean absolute error in the estimation of birth weight was $246.7 \mathrm{~g}$ [1, $865 \mathrm{~g}]$.

The mean percentage error for ultrasound estimated fetal weight was $1.9 \pm 11.4 \%$. This means that, in the overall study group, the ultrasonographic method slightly overestimated the actual birth weight. The mean absolute percentage error was 8.8 $\pm 7.5 \%$.

In the study, the percentage of estimates within \pm $10 \%$ of the actual birth weight was found to be $65 \%$. In $22.5 \%$ of the cases, ultrasound overestimated the birth weight. In average, ultrasound overestimated the birth weight by 250.2 g (CI: $166.4-333.9 \mathrm{~g}$ ). In $12.5 \%$ of the cases, ultrasound underestimated the birth weight. In average, ultrasound underestimated the birth weight by 241.9 g (CI: 137.5 - $346.5 \mathrm{~g}$ ). The above mentioned findings related to the accuracy of the ultrasound estimation are shown in Table 2 and 3.
Table 3: Error estimation

\begin{tabular}{|cc|} 
Characteristics & Number (\%) \\
\hline Accurate estimation & $78(65)$ \\
\hline Inaccurate estimation & $42(35)$ \\
- overestimation & $27(22.5)$ \\
- underestimation & $15(12.5)$
\end{tabular}

Estimation of fetal weight is a vital and universal part of antenatal care, not only in the management of labor and delivery but also during the management of high-risk pregnancies and growth monitoring. ${ }^{7}$

Very low birth weight babies who are delivered vaginally may be predisposed to skull injuries, limb fractures, and trauma to the abdominal organs such as spleen and liver because of prematurity. Birth weights of more than $4 \mathrm{~kg}$ have been associated with prolonged labor, operative or traumatic delivery, and fetal neurologic injury. ${ }^{8}$ Limiting the potential complications associated with the birth of both small and excessively large fetuses requires that accurate estimation of fetal weight occurs 
before decision to delivery is made. ${ }^{7}$ Likewise, accurate estimation of fetal weight is also very important in planning for a vaginal birth after a previous cesarean section and in the intrapartum management of fetuses with breech presentation. ${ }^{8}$ Currently available methods for assessing fetal weight in utero are subject to predictive errors. These methods include assessment of fetal size by tactile method which is done by the obstetrician or midwife, maternal self-estimation, and ultrasonography. ${ }^{9}$ Ultrasound estimation of fetal weight, while being accurate to a certain degree, is associated with error ranging from \pm 6 to $11 \%$ depending on parameters measured and the equation used for estimation. ${ }^{7}$ The aim of the present study was to find the accuracy and thus reliability of ultrasound in estimating the weight of the fetus which helps in the further management of the pregnancy.

This was a prospective cross-sectional study of 120 women with singleton term pregnancies leading to live birth. The mean actual birth weight in this study was $2822.5 \pm 407.7 \mathrm{~g}$. This is similar to the mean actual birth weight of $3070 \mathrm{~g}$ (2110-4900 g) reported by Bajhracharya et al..$^{5}$ in Kathmandu, Nepal. However, it is lower than $3202 \pm 547.9 \mathrm{~g}$ reported in West Indies, $3497 \pm 438 \mathrm{~g}$ reported in Croatia, $3561 \pm 415 \mathrm{~g}$ reported in France, and 3568 $\pm 496 \mathrm{~g}$ documented in the United Kingdom. The mean estimated fetal weight was $2863.5 \pm 441.9 \mathrm{~g}$ which was lower than the other studies done in different parts of the world. This difference in fetal weights may be due to several factors affecting birth weight such as regional and socioeconomic factors. $^{7}$

Different measures of accuracy were used in the statistical analysis and these include mean error, mean absolute error, mean percentage error, mean absolute percentage error, and the proportion of estimates within $\pm 10 \%$ of actual birth weight. Interestingly, the mean error can be misleading as it is the sum of positive and negative deviations from actual birth weight, thus artificially reducing the difference between actual birth weight and estimated birth weight. By contrast, the mean absolute percentage error reveals the variability noted regardless of their direction and, as such, is the best and much more accurate predictor of differences from actual birth weight. ${ }^{7}$

The mean percentage errors for ultrasound estimated fetal weight was $1.91 \pm 11.41 \%$. This means that, in the study group, the ultrasonic method slightly overestimated the actual birth weight. The mean absolute percentage error for ultrasound estimated weight was $8.76 \pm 7.51 \%$. In the studies done by Colman et al. ${ }^{10}$ Dimasi et al. ${ }^{11}$ Houze et al $^{12}$ and Lafont et al. $^{13}$ the mean absolute percentage errors by ultrasound method were found to be $7.0 \%, 5.71 \%, 7 \%$ and $7.2 \%$ respectively which were similar to our study. These results are also consistent with previously observed findings that the mean absolute percentage error of predicting birth weight varies from $6 \%$ to $12 \%$ of actual birth weight. ${ }^{7}$

Determination of weight within $10 \%$ of the actual birth weight was considered acceptable accuracy. ${ }^{5}$ In our study, the percentage of estimates within \pm $10 \%$ of the actual birth weight was found to be $65 \%$ which is similar to the findings of the study done by Bajracharya et al, ${ }^{5}$ Lafont et al. ${ }^{13}$ Dimasi et al., ${ }^{11}$ Bolanka et al. ${ }^{14}$ and Colman et al. ${ }^{10}$ in which the percentage of estimates within $\pm 10 \%$ of the actual birth weight were found to be $60 \%$, $69.1 \%, 69.6 \%, 72.25 \%$ and $75 \%$ respectively. These results are also consistent with what have been previously observed that $40-76 \%$ of the estimates were within $10 \%$ of actual birth weight. ${ }^{7}$ In our study, there was a strong positive correlation between EFW and $\mathrm{ABW}$ and there was no statistically significant difference between mean EFW and mean ABW ( $\mathrm{r}=0.71, \mathrm{p}<0.001)$ which was similar to the studies done by Dimasi et al11 $(\mathrm{r}=0.79)$, Frieri et al. ${ }^{15}(\mathrm{r}=0.96)$, Lafont et al. ${ }^{13}(\mathrm{r}=0.79)$ and other studies done by Simms et al. ${ }^{9}$ and Cletus et al. ${ }^{6}$ Our result, therefore, seems to agree with the opinion of some authors who reported that the use of ultrasonography to predict fetal weight was accurate in those populations.

\section{LIMITATIONS OF THE STUDY}

A major limitation of this study is the localized nature of the sample studied. The sample was drawn from a population of antenatal clinic attendees in just one tertiary hospital in Bharatpur, Nepal, therefore, the ability to generalize our results is obviously limited. Furthermore, we did not compare sonographic fetal weight estimated by Hadlock (BPD, AC) algorithm with any other algorithm to determine which algorithm may be more valid in the population. The scan-to-delivery interval of 0 to 7 days we adopted without adjustment may also have significantly influenced our measurements as it has been reported that fetal weight increases considerably from the 38 th week 
of gestation. The other limiting factors associated with the ultrasonographic prediction of fetal weight include imprecise imaging of fetal structures (due to limitations such as patient's obesity, placentation, oligohydramnios, and/or fetal position), unavoidable operator- and equipment-related measurement errors and approximations. It may be beneficial to take these factors into account and examine how they affected the fetal weight estimation. However, in spite of these limitations, our result suggests the use of ultrasonography for estimation of fetal weight in the population whenever available. ${ }^{11}$

\section{CONCLUSION}

Ultrasonographically estimated fetal weight positively and strongly correlated with the actual birth weight of fetuses in College of Medical Sciences, Bharatpur, Nepal. The use of Hadlock (BPD, AC) fetal weight estimation model, therefore, appears to be valid in the population studied. Furthermore, sonography appears to be an accurate predictor of both low and normal weight fetuses.

We, nevertheless, believe that a further study to compare sonographically estimated fetal weights with actual birth weight using different estimation models may still be necessary so as to determine which one is the best for Nepalese population.
9. DOI: $10.1155 / 2014 / 970973$.

8. Ugwu EO, Udealor PC, Dim CC, Obi SN, Ozumba BC, Okeke DO, et al. Accuracy of clinical and ultrasound estimation of fetal weight in predicting actual birth weight in Enugu, Southeastern Nigeria. Niger J Clin Pract. 2014;17(3):270-5. DOI: 10.4103/1119-3077.130208. PMID:24714001.

9. Stewart DS, Hunter T, Fletcher H, Dacosta V, Walters C, Reid M. Comparison of ultrasonographic estimated fetal weight and actual birthweight performed by residents in training at the University Hospital of the West Indies. West Indian Med J. 2013;62(9):831-4.

10. Colman A, Maharaj D, Hutton J, Tuohy J. Reliability of ultrasound estimation of fetal weight in term singleton pregnancies. NZ Med J. 2006;119(1241):U2146. PMID:16964298.

11. Dimassi K, Cadhi YE, Sahnoune R, Derbel M, Triki A, Romdhane HB. Accuracy of ultrasound estimated fetal weight performed by residents at delivery day. J Gynecol Obstet Biol Reprod. 2015;44(7):632-8. DOI: 10.1016/ j.jgyn.2014.10.015. PMID:25481768.

12. Houze A, Closset E, Deruelle P. Accuracy of ultrasound estimated fetal weight performed by OB-Gyn residents at due date. Gynecol Obstet Fertil. 2009;37(4):367-71.

13. Lafont M, Dellinger P, Mutumba W, Bernard C, Hoyek T. Accuracy of ultrasound estimated fetal weight at term. Gynecol Obstet Fertil. 2016;44(7-8):391-5. DOI: 10.1016/ j.gyobfe.2016.05.005. PMID:27426690.

14. Bolanca I, Kuna K, Herman R, Kosec V, Herman M. Ultrasonographic estimation of fetal weight - residents accuracy. Coll Antropol. 2005;2:465-8.

15. Freire DM, Cecatti JG, Paiva CS. Correlation between estimated fetal weight by ultrasound and neonatal weight. Rev Bras Ginecol Obstet. 2010;32(1):4-10. DOI: 10.1590/ S0100-72032010000100002. PMID:20209256.

\section{REFERENCES}

1. Sherman DJ, Arieli S, Tovbin J, Siegel G, Caspi E, Bukovsky I. A comparison of clinical and ultrasonic estimation of fetal weight. Obstet Gynecol. 1998;91(2):212 -7. DOI: 10.1016/S0029-7844(97)00654-6.

2. Kumari A, Goswami S, Mukherjee P. Comparative study of various methods of fetal weight estimation in term pregnancy. J South Asian Feder Obst Gynae. 2013;5(1):2225. DOI: 10.5005/jp-journals-10006-1213.

3. Wikstrom I, Bergstrom R, Bakketeig L, Jacobsen G, Lindmark G. Prediction of high birthweight from maternal characteristics, symphysis fundal height and ultrasound biometry. Gynecol Obstet Invest. 1993;35(1):27-33. DOI: 10.1159/000292658. PMID:8449430.

4. Melamed N, Yogev Y, Meizner I, Mashiach R, Bardin R, Haroush AB. Sonographic fetal weight estimation which model should be used? J Ultrasound Med. 2009;28:617-29. PMID:19389901

5. Bajracharya J, Shrestha NS, Karki C. Accuracy of prediction of birth weight by fetal ultrasound. Kathmandu Univ Med J. 2012;10(38):74-6. DOI: 10.3126/ hren.v10i3.7053.

6. Eze CU, Abonyi LC, Njoku J, Okorie U, Owonifari O. Correlation of ultrasonographic estimated fetal weight with actual birth weight in a tertiary hospital in Lagos, Nigeria. Afri Health Sci. 2015;15(4):1112-22. DOI: 10.4314/ ahs.v15i4.9. PMID:2695801.

7. Njoku C, Emechebe C, Odusolu P, Abeshi S, Chukwu C, Ekabua J. Determination of accuracy of fetal weight using ultrasound and clinical fetal weight estimations in Calabar South, South Nigeria. Int Sch Res Notices. 2014;2014:234- 